Eixo Temático: Desenvolvimento de Estratégias Didáticas

ET-07-005

\title{
UTILIZANDO O LUDICO PARA O ENSINO DE CIÊNCIAS E BIOLOGIA NO ENSINO FUNDAMENTAL SOBRE ANATOMIA DO SISTEMA RESPIRATÓRIO.
}

Aline Guedes do Nascimento

Universidade Federal de Pernambuco. E-mail: guedesaline85@gmail.com.

http://dx.doi.org/10.21472/congrebio2016.et-07-005

\section{RESUMO}

A utilização do lúdico como forma de ensino e aprendizado faz com que os alunos tenha a possibilidade de vivência da proposta de um conteúdo ou assunto de forma mais abrangente e visual, e não apenas como uma forma inatingivel. Para o ensino de Ciências deve-se trazer a Ciência para sala de aula ou vise e versa, apenas assim se tem a possibilidade de garantir a realidade aos alunos e que os mesmo consigam tirar suas deduções de um determinado ponto de vista. Desta forma, foi realizada uma atividade utilizando materiais para a construção do sistema respiratório visando à construção de um material onde os alunos vão vivenciar teoria e prática em sala de aula, assim trazendo a Ciência para sala de aula de forma mais lúdica.

Palavra-Chave: Lúdico; Materiais e atividade.

\section{INTRODUÇÃO}

O presente trabalho refere-se à formação de estruturas de anatomia do sistema respiratário, feita pelos alunos envolvidos na atividade. Esse trabalho foi realizado com alunos da $7^{a}$ série do Ensino Fundamental, da Escola Souza Veras, que fica localizada na Cidade da Varzea, em Recife, Pernambuco.

Desta forma, os alunos tem a oportunidade de fazer e executar o próprio material didático, para um melhor aprendizado do conteúdo em questão, fazendo com que não sejam apenas coajuvantes, mas sim protagonistas na execução do trabalho envolvido.

Segundo Freire (1996), o professor age de forma como quem deposita apenas um conhecimento, na qual esquece muitas vezes que o professor deve ser um orientador nessa caminhada, deixando que os envolvidos desenvolva suas teorias diantes de assuntos e construção de materiais. Visando ao desenvolvimento dos alunos, a construção faz com que sintam capazes de produzir e desenvolver o sistema respiratório e até mesmo outros de forma participativa e não apenas observador de um sistema respiratório.

As aulas muitas vezes é considera pelos alunos como algo monótono, maçante e chato. Desta forma, muitas vezes os estudantes acabam indo para o centro educacional apenas por obrigação dos seus pais e sociedade de modo geral. Por essas e outras e que atividades que envolvam o lúdico pode ajudar muito os alunos a ter um ambiente escolar mais agradável.

Para Freinet (1998) o lúdico é: “(...) um estado de bem-estar que é a exacerbação de nossa necessidade de viver, de subir e de perdurar ao longo do tempo, desta forma, a escola tem o papel de criar um ambiente lúdico para o desenvolvimento das aulas trazendo assim conceitos estrenos de sala de aula e também possibilitando um processo de ensino-aprendizagem prazeroso. 


\section{OBJETIVOS}

O objetivo do trabalho foi fazer com que os alunos da Escola SouzaVeraz desenvolvam uma atividade prática para construção do seu conhecimento;

Desenvolver a criatividade dos alunos diante de assuntos e conteúdos importantes, mas que muitas vezes é deixado de lado como os sistemas que envolve o corpo humano;

Fazer com que os alunos tenham o poder de construir suas conclusões diante de assuntos que muitas vezes é visto pelos alunos como decorar o que está no livro;

Fazer com que eles trabalhem em conjunto também faz parte do desenvolvimento diante da sociedade e seus conflitos.

\section{MATERIAIS E METODOLOGIA}

A atividade de construção do material didático foi feito na Escola Souza Veraz, que fica na Varzea na Cidade de Recife, Pernambuco. Foi realizada essa atividade prática pela cadeira da faculdade de Estágio de Ensino e Biologia 3, UFPE (Universidade Federal de Pernambuco), na qual estava fazendo um estágio curricular para concluir o meu estágio no ensino e Biologia.

A produção de um material didático a partir de massa de modelar para a construção de um sistema respiratório, muitas vezes esses materias não são levados a sério, mas esses e outros podem sim ajudar fazendo com que os alunos crie sistemas ou até mesmo outras estruturas. Foi utilizado massa de modelar em várias cores para que os alunos construam o sistema respiratório que vai desde estruturas mais visíveis até outras estruturas como os alveólos que são mais microscópicas.

Eles foram divididos em quatro grupos, que receberam uma caixa de massa de modelar, contendo doze unidades de várias cores. Também receberam uma lista de atividades onde eles tinham que responder algumas questões que envolvia o sistema respiratório e também tinha uma questão aberta onde eles mesmos tinham que elaborar a pergunta e a resposta.

O primeiro passo foi a construção do material com a massa de modelar, onde foi utilizado uma aula e dez minutos para construção, depois foi utilizado meia hora para responder às questões e depois concluir atividade fazendo a elaboração de uma questão e respondê-la.

\section{RESULTADOS E DISCUSSÃO}

Além de ser gratificante, a prática da Ciência é muito importante para a construção e afirmação do aprendizado construído em sala de aula. Onde os alunos interagiram trabalhando em grupo, no qual cada um de seus componentes ajudava-se com o que cada um sabia a respeito do assunto. Fazer com que os alunos construam e desenvolva faz com que eles não esqueçam o conteúdo proposto e podem fazer também a sua construção, desta forma tanto o sistema positivista quando o construtivista nessa atividade é levado em consideração.

Além disso, os alunos têm uma relação mais próxima dos seus colegas e em conjunto resolverem como iram fazer atividade, a cor escolhida e responder as questões.

\section{CONCLUSÕES}

A realização dessa atividade permitiu levar os alunos a pensar, debater e justificar suas ideias e aplicar seus conhecimentos em situações novas, usando os conhecimentos teóricos e práticos sobre o sistema respiratório dentro do ensino de Ciências. O tema proposto foi criado pensando-se em algo que estivesse de acordo com a realidade dos alunos e considerando estruturas já existentes de sistema respiratório e tudo que poderia ser acrescentado pelos alunos na construção do conhecimento. 


\section{REFERÊNCIAS}

AIRES, M. M. Fisiologia. 3 ed.

FREIRE, P. Pedagogia da Autonomia. Saberes necessários à prática educativa. São Paulo: Paz e Terra, 1996.

KNECHTEL, C. M.; BRANCALHÃO, R. M. C. Estratégias lúdicas no ensino de Ciências. 2009. 